\title{
Primary cardiac amyloidosis in a young man presenting with angina pectoris
}

\author{
STEPHEN SALTISSI, PAUL J KERTES, DESMOND G JULIAN \\ From the University Department of Cardiology, Freeman Hospital, Newcastle upon Tyme
}

SUMMARY A 32 year old man presenting with typical angina pectoris was found to have primary cardiac amyloidosis. Myocardial infiltration was strongly suggested by echocardiography, and a histological diagnosis was confirmed by renal biopsy. Nevertheless, technetium pyrophosphate myocardial scanning, recently proposed as a sensitive non-invasive test, showed negative results despite widespread cardiac involvement confirmed at necropsy after unexpected sudden death. Postmortem findings also showed subintimal amyloid material in a severely narrowed right coronary artery. This case highlights several unusual clinical features in a patient with advanced primary cardiac amyloidosis.

Primary cardiac amyloidosis is a rare disease, which usually presents with heart failure in the middle and later years of life. Presentation with angina pectoris has been reported rarely. Although the therapeutic options are limited and the treatment generally unsatisfactory, the antemortem diagnosis of primary cardiac amyloidosis is important to exclude potentially remediable conditions which it may mimic. Haemodynamic values obtained at cardiac catheterisation are diagnostically unreliable as they may not clearly differentiate restriction from pericardial constriction. ${ }^{1}$ Thus the diagnostic value of several noninvasive investigations has been studied, including echocardiography ${ }^{2-4}$ and radionuclide myocardial imaging. ${ }^{5-8}$ In particular, the sensitivity and specificity of technetium- $99 \mathrm{~m}$ pyrophosphate myocardial scintigraphy are reported to be high. ${ }^{8}$

We report the case of a patient presenting with angina, in whom primary cardiac amyloidosis was indicated by echocardiography but not by myocardial scanning.

\section{Case report}

A 32 year old white man presented with a four month history of progressively increasing chest pain on exertion which was typical of angina pectoris. He was a non-smoker with no relevant medical or family his-

Requests for reprints to Professor D G Julian, University Department of Cardiology, Freeman Hospital, Newcastle upon Tyne NE7 7DN. tory. Exertional chest tightness radiating to both arms was first noted four months before admission and had gradually increased in severity. Preliminary investigations had shown a nephrotic syndrome with $6.7 \mathrm{~g}$ urinary protein loss per 24 hours with otherwise normal renal function determined biochemically and by intravenous pyelography.

On examination he was normotensive with a sinus tachycardia of 100 beats/min. The jugular venous pressure was slightly raised with a prominent "a" wave. The apical impulse was not easily felt, and on auscultation a third heart sound was audible with no murmurs. The lung fields were clear, and the liver, spleen, and kidneys were all impalpable.

\section{INVESTIGATIONS}

The electrocardiogram showed sinus rhythm with an axis of $+100^{\circ}$. There was a $Q$ wave in leads $V 1$ and V2 with clockwise rotation. Downsloping ST depression and $T$ wave inversion were prominent in the anterolateral leads. The complexes were reduced in amplitude in the limb leads only. The chest $x$ ray film showed prominence of the upper lobe vessels with small bilateral pleural effusions; these changes cleared rapidly after treatment with an oral diuretic. The cardiothoracic ratio was 0.5 . An echocardiogram showed a pronounced concentric increase in both left and right ventricular wall thickness (Figure), and the myocardium appeared to be granular with echo dense speckling. Left ventricular cavity size was normal, and a small pericardial effusion was evident. The $M$ mode echocardiograms of left ventricular wall motion 


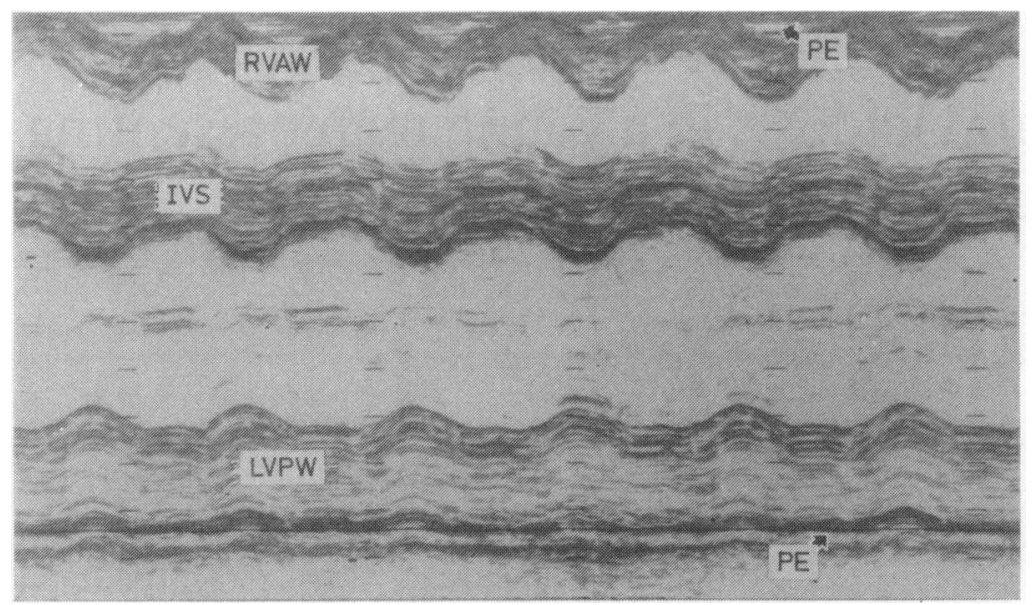

Figure Parasternal $M$ mode echocardiogram showing pronounced thickening of the interventricular septum (IVS $15 \mathrm{~mm}$, normal $\leqslant 11 \mathrm{~mm})$, left ventricular posterior wall (LVPW $19 \mathrm{~mm}$, normal $\leqslant 11 \mathrm{~mm}$ ), and right ventricular anterior wall (RVAW). A small pericardial effusion is visible $(P E)$. The left ventricular end diastolic dimension of $43 \mathrm{~mm}$ is within the normal range (up to $52 \mathrm{~mm}$ ), but the end systolic dimension of 29 mon yields a subnormal fractional shortening of $25 \%$ (normal $\geqslant 28 \%$ ).

were digitised and showed a reduced fractional circumferential fibre shortening of $25 \%$ (normal $\geqslant 28 \%$ ) and subnormal maximum velocities of left ventricular systolic and diastolic dimension change of $9.2 \mathrm{~cm} / \mathrm{s}$ and $9.7 \mathrm{~cm} / \mathrm{s}$ respectively (normal $>10 \mathrm{~cm} / \mathrm{s}$ ).

A technetium $-99 \mathrm{~m}$ pyrophosphate myocardial scan was negative, the myocardial uptake of the tracer $(1+)$ being of a lesser intensity than that of the rib cage. The peripheral blood film was normal and the erythrocyte sedimentation rate $24 \mathrm{~mm}$ in the first hour. Serum electrolyte concentrations and liver function tests were normal apart from moderate hypoalbuminaemia. A repeat 24 hour urine collection showed $14.8 \mathrm{~g}$ protein, and numerous red blood cell casts were present in the urinary sediment. Plasma concentrations of IgG, IgA, and IgM were all appreciably reduced, and immunoelectrophoresis showed a band of free $\lambda$ chains. A renal biopsy was performed and showed early glomerular and vascular amyloid deposition. Immunofluorescence was negative.

In view of these findings a diagnosis of amyloidosis with cardiac involvement was thought likely, and cardiac catheterisation was not performed. After a rapid initial response to frusemide and nitrates the patient was discharged from hospital with an early outpatient review planned to consider treatment with colchicine. Unfortunately, he died suddenly at home two days later.

\section{NECROPSY FINDINGS}

Postmortem examination confirmed biventricular enlargement with the heart weighing $500 \mathrm{~g}$. The wall of the right coronary artery was appreciably thickened halfway along its length with the lumen greatly reduced. Minor atheroma was seen in the left anterior descending artery. There was a moderate amount of clear pericardial fluid, and the lungs were congested. The spleen was enlarged and of waxy consistency, as were the kidneys. Histological examination showed extensive diffuse deposition of amyloid material in the kidneys, spleen, and throughout the myocardium. Subintimal amyloid material was found in the obstructing lesion in the right coronary artery. Bone marrow examination was normal.

\section{Discussion}

This report of a patient with primary cardiac amyloidosis confirmed at necropsy highlights several unusual features, which may be of importance with respect to the clinical presentation and non-invasive diagnosis of this condition. Primary cardiac amyloidosis is usually regarded as a disease of later life with a mean age at diagnosis of 61 years, over $98 \%$ of patients presenting at $\geqslant 40$ years of age. 910 This case in a 32 year old patient, together with reports of primary cardiac amyloidosis presenting in childhood, ${ }^{1112}$ however, emphasises that the diagnosis is possible at all ages.

Congestive cardiac failure is the commonest mode of presentation, occurring in $80 \%$ or more of patients with primary cardiac amyloidosis. ${ }^{13} 14$ Typical anginal chest pain has been reported but is rarely the presenting symptom. In a recent study of 70 patients with systemic amyloidosis, $\mathbf{1 0}^{10}$ angina occurred in four of 20 patients with primary amyloidosis and was the presenting symptom in only one. The pathogenesis of the angina is thought to be widespread amyloid infiltration in the adventitia and media of small intramural coronary arteries. ${ }^{1013}$ Intimal deposits of sufficient degree appreciably to narrow such vessels are found less frequently, occurring in five of 15 patients with 
cardiac amyloidosis in one study. ${ }^{13}$ In another necropsy study ${ }^{15}$ similar lesions producing focal subendocardial ischaemic injury were found in only five of 108 patients with cardiac amyloidosis. In none of the patients in these studies could the angina be attributed to disease of the larger epicardial coronary arteries. In a recent report of 54 patients with cardiac amyloidosis studied at necropsy, ${ }^{14}$ only four experienced typical angina at some time in their illness and in only two were the epicardial coronary arteries obstructed, by atherosclerotic plaque in both cases. The present report emphasises the fact that cardiac amyloidosis may present with typical angina of effort, which may be due to lesions containing amyloid in major coronary arteries as well as to diffuse myocardial infiltration.

The definitive diagnosis of primary amyloidosis rests with tissue biopsy. Although renal and liver biopsy confirm the diagnosis in $90 \%$ and $95 \%$ of cases respectively, ${ }^{16}$ these procedures are not without risk. Rectal biopsy is safer but less sensitive, being diagnostic in only $60-80 \%$ of cases. ${ }^{16}$ Endomyocardial biopsy has also occasionally proved useful in patients with signs of cardiovascular involvement, but it also carries an appreciable risk and requires appropriate facilities and expertise. Recent interest has, therefore, focused on the non-invasive diagnosis of cardiac amyloidosis, in particular by echocardiography ${ }^{2-4}$ or technetium-99m pyrophosphate myocardial imaging..$^{5-8}$ Typically, echocardiography shows increased left and right ventricular wall thickness and reduced systolic left ventricular wall thickening in over $75 \%$ of patients. ${ }^{4}$ Global reduction of left ventricular function, left atrial enlargement, and pericardial effusions are found in most patients. Left ventricular diastolic function has been found to be more prominently impaired in patients with cardiac amyloidosis than in control subjects with aortic stenosis or hypertrophic cardiomyopathy. ${ }^{2}$ Although considerable overlap existed between these groups, the results highlight the importance of restricted diastolic filling due to myocardial amyloid deposition. Some workers have claimed that the granular sparkling appearance found in thickened ventricular muscle on cross sectional echocardiography in patients presenting with unexplained cardiac failure is virtually diagnostic of cardiac amyloidosis, ${ }^{4}$ although others regard this appearance as non-specific, occurring in other forms of infiltrative cardiomyopathy, hypertrophic cardiomyopathy, and even chronic renal failure. ${ }^{3}$

With technetium-99m pyrophosphate imaging diffuse and intense accumulation of myocardial tracer has been reported in primary cardiac amyloidosis ${ }^{5-8}$ with increased specificity when uptake is biventricular. ${ }^{6}$ In a study of 20 patients with cardiac amyloidosis confirmed by biopsy, ${ }^{8}$ tracer uptake of intensity equal to or greater than that of the ribs $(3+$ or $4+)$ was found in nine of 11 patients with abnormal echocardiograms but in only two of nine with normal echocardiograms, the extent of uptake correlating with wall thickness. Consequently, myocardial imaging has been advocated as a sensitive ( $89 \%$ ) and specific $(100 \%)$ diagnostic test for primary cardiac amyloidosis, which is of particular value in moderately advanced cases with echocardiographic abnormalities. ${ }^{8}$ In contrast, in our patient with advanced myocardial disease and widespread typical echocardiographic features technetium pyrophosphate imaging was negative. This finding highlights the limitations of this technique in diagnosing primary cardiac amyloidosis in individual patients.

Primary cardiac amyloidosis may, therefore, present with typical angina pectoris, even in young men. Non-invasive test results may point to the diagnosis when positive but do not exclude the presence of even advanced disease when negative. Histological examination of appropriate tissue biopsy specimens remains the definitive diagnostic test.

PJK is supported by the Australian National Heart Foundation.

\section{References}

1 Swanton RH, Brooksby IAB, Davies MJ, Coltart DJ, Jenkins BS, Webb-Peploe MM. Systolic and diastolic ventricular function in cardiac amyloidosis. Studies in six cases diagnosed with endomyocardial biopsy. Am $\mathcal{f}$ Cardiol 1977; 39: 658-64.

2 St John Sutton MG, Reichek N, Kastor JA, Giuliani ER. Computerised M-mode echocardiographic analysis of left ventricular dysfunction in cardiac amyloid. Circulation 1982; 66: 790-9.

3 Bhandari AK, Nanda NC. Myocardial texture characterization by two-dimensional echocardiography. Am $\mathfrak{f}$ Cardiol 1983; 51: 817-25.

4 Siqueira-Filho AG, Cunha CLP, Tajik AJ, Seward JB, Schattenberg TJ, Giuliani ER. M-mode and twodimensional echocardiographic features in cardiac amyloidosis. Circulation 1981; 63: 188-96.

5 Wizenberg TA, Muz J, Sohn YH, Samlowski W, Weissler AM. Value of positive myocardial technetium-99mpyrophosphate scintigraphy in the noninvasive diagnosis of cardiac amyloidosis. Am Hean $\mathcal{F}$ 1982; 103: 468-73.

6 Schiff S, Bateman T, Moffatt R, Davidson R, Berman $D$. Diagnostic considerations in cardiomyopathy: unique scintigraphic pattern of diffuse biventricular technetium- $99 \mathrm{~m}$-pyrophosphate uptake in amyloid heart disease. Am Heart $\mathcal{F}$ 1982; 103: 562-3.

7 Sobol SM, Brown JM, Bunker SR, Patel J, Lull RJ. Noninvasive diagnosis of cardiac amyloidosis by technetium-99m-pyrophosphate myocardial scintigraphy. Am Heart f 1982; 103: 563-6. 
8 Falk RH, Lee VW, Rubinow A, Hood WB Jr, Cohen AS. Sensitivity of technetium-99m-pyrophosphate scintigraphy in diagnosing cardiac amyloidosis. Am $\mathcal{J}$ Cardiol 1983; 51: 826-30.

9 Kyle RA. Amyloidosis. Clin Haematol 1982; 11: 151-80.

10 Wright JR, Calkins E. Clinical-pathologic differentiation of common amyloid syndromes. Medicine (Baltimore) 1981; 60: 429-48.

11 Hake H, Goll U, Thoenes W. Primary perireticulin amyloidosis in a 14-year old girl. Eur F Pediatr 1976; 124: 43-9.

12 Pick AI, Versano I, Schreibman S, Ben-Bassat M, Shoenfeld Y. Agammaglobulinemia, plasma cell dys- crasia, and amyloidosis in a 12-year old child. Am $\mathcal{F}$ Dis Child 1977; 131: 682-6.

13 Buja LM, Khoi NB, Roberts WC. Clinically significant cardiac amyloidosis. Clinicopathologic findings in 15 patients. Am F Cardiol 1970; 26: 394-405.

14 Roberts WC, Waller BF. Cardiac amyloidosis causing cardiac dysfunction: analysis of 54 necropsy patients. Am f Cardiol 1983; 52: 137-46.

15 Smith RRL, Hutchins GM. Ischemic heart disease secondary to amyloidosis of intramyocardial arteries. $A m \mathcal{F}$ Cardiol 1979; 44: 413-7.

16 Kyle RA, Bayrd ED. Amyloidosis: review of 236 cases. Medicine (Baltimore) 1975; 54: 271-99. 